\title{
Ceruloplasmin as a Predictor for Responsiveness to Direct Antiviral Drugs in Treatment of Chronic HCV Infection
}

Mohammed Salah Hussein ${ }^{1}$, Asem Ashraf Mahmoud ${ }^{4}$, Abdel Rahman Ibrahim ${ }^{5}$, Mohammed Saied Bakeer', Safaa Abd Elsalam Hussein ${ }^{6}$, Abdelhalim Assem Mahmoud ${ }^{2}$, Tarek Eldahshan ${ }^{3}$

${ }^{1}$ Department of Internal Medicine, ${ }^{2}$ Department of Tropical Medicine, ${ }^{3}$ Department of Clinical Pathology, Faculty of Medicine, Al-Azhar University, ${ }^{4}$ Department ofGastroenterology and Hepatology, Military Medical Academy,

${ }^{5}$ Department of Internal Medicine,Algalaa Military Hospital, ${ }^{6}$ Department of Internal Medicine, Faculty of

Medicine, Ain Shams University

Corresponding author: Mohammed Salah Hussein, email: dr_msalahali@azhar.edu.eg

\begin{abstract}
ABSTACT
Background: Hepatitis $\mathrm{C}$ virus (HCV) is one of the major globally cause of death and morbidity .

The appearance of direct-acting antiviral agents (DAAs), which specifically target HCV proteins, has provided insights into the current situation Ceruloplasmin $(\mathrm{Cp})$, where its serum levels tend to be high in myocardial infarction, neoplastic and inflammatory conditions.

Objective: The aim of the current work was to evaluate the prognostic value of serum ceruloplasmin in chronic hepatitis $\mathrm{C}$ before and after treatment by direct-acting antiviral agents and possibility of using it as a marker for hepatitis $C$ virus treatment response.

Patients and methods: This intervention prospective study was conducted on one hundred subjects attending at the Hepatology Clinic at the Hepatology Clinic at Algalaa Military Hospital and Kopri Elkopa Military Hospital and Al-Hussein university Hospital, from December 2016 till June 2017. The associations between serum Ceruloplasmin levels in chronic HCV patients before receiving DAAS and three months after was investigated.

Results: showed that serum Ceruloplasmin levels were slightly higher after receiving DAAS and so it can be used as a marker for responsiveness to direct acting antiviral drugs.

Conclusion: It could be concluded that ceruloplasmin can be used as a marker for responsiveness to direct acting antiviral drugs.
\end{abstract}

Keywords: Ceruloplasmin; Hepatitis C virus; Direct acting antiviral agents.

\section{INTRODUCTION}

Hepatitis $\mathrm{C}$ virus (HCV) is one of the leading causes of death and morbidity in the world. It is estimated that about $3 \%$ of the world's population and about 130-170 million people, are infected with this virus. Of them, $30 \%$ will get liver cirrhosis and $2 \%$ will develop liver cancer ${ }^{(\mathbf{1})}$.

Hepatitis C virus (HCV) still affects a large proportion of the Egyptian population. It is estimated that in the 1-59 age group, 5.3 million people are infected with the virus. Approximately 3.7 million HCV RNA is positive ${ }^{(2)}$.

Peginterferon Alfa plus ribavirin (pegIFN / $\mathrm{RBV}$ ) is traditionally used to treat the hepatitis C virus (HCV). However, this system has limited viral response rates of $40 \%-50 \%$ and is associated with a high frequency of adverse events ${ }^{(3)}$.

The use of direct acting agents has revolutionized the treatment of chronic hepatitis C (HCV). Oral therapy is not only effective, but safe and tolerable ${ }^{(4)}$.

The appearance of direct-acting antiviral agents (DAAs), which specifically target HCV proteins, has provided insights into the current situation, The use of protease inhibitors, such as Telaprevir, Boceprevir, Simeprevir, Faldaprevir and Vaniprevir, in combination with Peginterferon and Ribavirin has improved treatment efficacy in treatment-naïve patients $(70 \%$ to $80 \%)$ and in patients infected with
HCV genotype 1 who have relapsed posttreatment ${ }^{(5)}$.

Ceruloplasmin acts as a ferroxidase and increases during inflammation, and other conditions, and these observations seem to suggest that ceruloplasmin is likely to act as an antioxidant and an acute reactive agent ${ }^{(6)}$.

Serum ceruloplasmin is typically decreased in patients with Wilson's disease and other conditions characterized by marked renal or enteric protein loss, including severe end-stage liver disease of any etiology and in some rare neurologic diseases ${ }^{(7)}$. Patients with severe hepatitis were shown to have significantly lower levels of Ceruloplasmin compared to patients with other liver diseases, except for Wilson's disease ${ }^{(\mathbf{8})}$.

The aim of the current work was to evaluate the prognostic value of serum ceruloplasmin in chronic hepatitis $\mathrm{C}$ before and after treatment by direct-acting antiviral agents and possibility of using it as a marker for hepatitis $\mathrm{C}$ virus treatment response.

\section{SUBJECTS AND METHODS}

This intervention prospective study included a total of one hundred subjects recently discovered hepatitis $\mathrm{C}$ virus (HCV) attending at the Hepatology Clinic at Algalaa Military Hospital and Kopri Elkopa Military Hospital and Al-Hussein university 
Hospital. Approval of the ethical committee and a written informed consent from all the subjects were obtained. This study was conducted between December 2016 till June 2017.

The subjects were only one group; recently discovered hepatitis $\mathrm{C}$ virus (HCV) and classified Child A according to Child Pugh score and attending at hospitals for further investigations and receive direct-acting antiviral agents (DAAs) (Daclatasvir \& Sofosbuvir) regimen. Their age was ranged from 25 to 68 years and they were 74 males and 26 females.

All patients showed negative history and lab results for hepatitis B virus (HBV), ANA, HIV and alpha fetoprotein and no family history of Wilson disease. On examination, there was no ascites or lower limb edema, no jaundice and they were vitally stable. Females were not pregnant and not on contraceptive pills.

\section{Exclusion criteria}

- Patients with non-hepatitis $\mathrm{C}$, chronic liver disease or renal disease.

- Patients with any organ failure, malignancy or evidence of inflammatory or autoimmune diseases.

- Patients infected by other hepatic virus or Human immune deficiency virus (HIV).

- Patients were diagnosed as autoimmune hepatitis or ANA positive.

- Hepatocellular carcinoma.

- Patients complaining of Obstructive jaundice.

- Family history or clinical picture of Wilson's disease.

- Pregnant women or use of oral contraceptive pill.

- Rheumatoid arthritis.

- Evidence of hepatic encephalopathy.

- Patient with hypoproteinemia of any cause.

\section{All participants were subjected to the following Clinical and Laboratory procedures:}

1. Full clinical history.

2. Full clinical examination including blood pressure, cardiac, chest and abdominal examination.

3. Body mass index (BMI) measurement.

4. Fasting and two hours postprandial blood glucose level for known diabetic patients and random blood sugar for others.

5. Blood picture, Liver and kidney function tests, prothrombin time (INR), bilirubin; total and direct, albumin, alpha fetoprotein, ANA, total proteins, globulins and hepatitis $\mathrm{C}$ virus (HCV) PCR, HBsAg and HIV.

6. Pelvic abdominal ultra sound.

7. Ceruloplasmin before receiving direct-acting antiviral agents (DAAs) (Daclatasvir \& Sofosbuvir) regimen and 3 months after. It is measured according to the method of G. Curzon and L. Vallet ${ }^{(9)}$.

\section{Statistical analysis}

Recorded data were analyzed using the statistical package for social sciences, version 20.0 (SPSS Inc., Chicago, Illinois, USA). Quantitative data were expressed as mean \pm standard deviation (SD). Qualitative data were expressed as frequency and percentage.

\section{The following tests were done:}

- Independent-samples t-test of significance was used when comparing between two means.

- Chi-square $\left(x^{2}\right)$ test of significance was used in order to compare proportions between two qualitative parameters.

- The confidence interval was set to $95 \%$ and the margin of error accepted was set to $5 \%$. The $p$-value was considered significant as the following:

- Probability (P-value)

-P-value $<0.05$ was considered significant.

-P-value $<0.001$ was considered as highly significant.

-P-value $>0.05$ was considered insignificant.

\section{RESULTS}

This study involved a total of 100 individuals in one group which recently discovered hepatitis $\mathrm{C}$ virus (HCV) and attending to hospital for further investigations and receive direct-acting antiviral agents (DAAs) (Daclatasvir \& Sofosbuvir) regimen. They were 74 males with average BMI of $(27.09 \pm$ $2.610 \mathrm{~kg} / \mathrm{m}^{2}$ ) and 26 females with average BMI of $\left(28.44 \pm 2.610 \mathrm{~kg} / \mathrm{m}^{2}\right)$. Their age was ranged from 25 to 68 years with average of $(48.91 \pm 8.928 \mathrm{~kg})$. Their Ceruloplasmin level before receiving DAAS was $(21.5 \pm 5.4)$ for males and $(27.12 \pm 4.36)$ for females, and after three months of receiving DAAS was $(24.32 \pm 5.24)$ for males and $(29.01 \pm 4.25)$ for females and ratio of increasing Ceruloplasmin level was $(13.91 \% \pm 0.075)$ for males and $(7.37 \% \pm 0.05)$ for female.

\section{The tables in this study show:}

Show Ceruloplasmin level before receiving DAAS are $(21.5 \pm 5.4)$ for males and $(27.1 \pm 4.36)$ for females, and after three months of receiving DAAS are (24.32 \pm 5.24$)$ for males and $(29.01 \pm 4.25)$ for females and ratio of increasing Ceruloplasmin level is $(13.9 \pm 0.07)$ for males and $(7.37 \pm 0.05)$ for female.

Comparing Ceruloplasmin concentrations and patient's gender, respectively 26 females and 74 males, it is interesting to note that females patients exhibited slightly higher Ceruloplasmin concentrations (ave \pm SD of $27.12 \pm 4.369 \mathrm{mg} / \mathrm{dL}$ ) than males patients $(21.35 \pm 5.4 \mathrm{mg} / \mathrm{dL})$ that were statistically significant at 5\% significance level (98 degrees of freedom, $t_{\text {stat }}$. 5.261, $\mathrm{t}_{\text {crit }} 1.67$, probability for a two-tail test was 0.00487).(Table 2 ),(Figure 2). 
Correlation between ceruloplasmin concentration and patient's age across 100 patients who were 46 patients under age of 48 yrs. and 54 patients above age of 48 yrs., the average Ceruloplasmin concentration was $(23.62 \pm 5.91$ $\mathrm{mg} / \mathrm{dL})$ and $(22.43 \pm 4.97 \mathrm{mg} / \mathrm{dL})$ for patients $<48$ yrs. and $>48$ yrs., respectively ( $t_{\text {stat. }}$ of 1.03 is less than $\mathrm{t}_{\text {crit }} 1.661, \mathrm{p}$ for a two-tail test was 0.303 , indicating that the results were not statistically different at 5\% significance level (98 degrees of freedom). (Table 5),(Figure 3 ), and Correlation between Ceruloplasmin concentration increasing rate and patient's age $<45$ yrs., patients between 45 yrs. and patients $52 \mathrm{yrs}$. and patients $>52 \mathrm{yrs}$. using ANOVA test(Figure 4).

Comparing Ceruloplasmin concentrations difference for all patients before receiving DAAS and after three months of receiving it, respectively
100 patients ( 26 females and 74 males), it is interesting to note that ceruloplasmin concentrations after receiving DAAS was $25.54 \pm 5.94 \mathrm{mg} / \mathrm{dL}$ which is slightly higher than before receiving DAAS $(22.98 \pm 6.1 \mathrm{mg} / \mathrm{dL})$ that were statistically significant at 5\% significance level (Table 1) and (Figure 1).

We have observed that the increasing rate of ceruloplasmin concentrations is greater in male (2.7 $\pm 1.4 \mathrm{mg} / \mathrm{dL})$ than in females $(1.89 \pm 1.28 \mathrm{mg} / \mathrm{dL})$ that were statistically significant at $5 \%$ significance level. (Table 2) and (Figure 2).

Finally we have also observed that no relations between increasing rate of Ceruloplasmin after receiving DAAS and age, The average of increasing rate of Ceruloplasmin concentration was $(2.5 \pm 1.43$ $\mathrm{mg} / \mathrm{dL})$ and $(2.6 \pm 1.51 \mathrm{mg} / \mathrm{dL})$ for patients $<48 \mathrm{yrs}$. and $>48$ yrs., respectively. (Table 4 ) and (Figure 3).

Table :(1) Shows ceruloplasmin concentrations

\begin{tabular}{|c|c|c|c|c|}
\hline \multirow{2}{*}{ Groups } & \multicolumn{2}{|c|}{ Ceruloplasmin (CP) } & \multicolumn{2}{c|}{ ANOVA } \\
\cline { 2 - 3 } & Range & Mean \pm SD & F & $\begin{array}{c}\text { P- } \\
\text { value }\end{array}$ \\
\hline Male & $13.2-2.4$ & $21.53 \pm 5.4$ & 10.15 & 0.0024 \\
\hline Female & $13-34$ & $27.123 \pm 4.3$ & & \\
\hline
\end{tabular}

Table (1) Show that female patients exhibited slightly statistically higher ceruloplasmin concentrations $(27.123 \pm 4.369 \mathrm{mg} / \mathrm{dL})$ than male patients $(21.35 \pm 5.401 \mathrm{mg} / \mathrm{dL})(\mathrm{P}<0.05)$.

Table :(2) Shows ceruloplasmin concentrations before receiving DAAS and after 3 months.

\begin{tabular}{|c|c|c|c|c|}
\hline \multirow{2}{*}{ Groups } & \multicolumn{2}{|c|}{ Ceruloplasmin $(\mathbf{C P})$} & \multicolumn{2}{c|}{ ANOVA } \\
\cline { 2 - 4 } & Range & Mean \pm SD & F & P-value \\
\hline $\begin{array}{c}\text { Ceruloplasmin before } \\
\text { receiving DAAS }\end{array}$ & $13.2-42.4$ & $22.98 \pm 5.4$ & 10.63 & 0.0013 \\
\hline $\begin{array}{c}\text { Ceruloplasmin after 3 } \\
\text { months of receiving DAAS }\end{array}$ & $14.6-43$ & $25.545 \pm 5.4$ & & \\
\hline
\end{tabular}

Table (2) Shows a statistically significant difference as regards Ceruloplasmin (CP) level before receiving DAAS $(22.98 \pm 5.4) \&$ after 3 months of receiving it $(25.54 \pm 5.7)(\mathrm{P}<0.05)$.

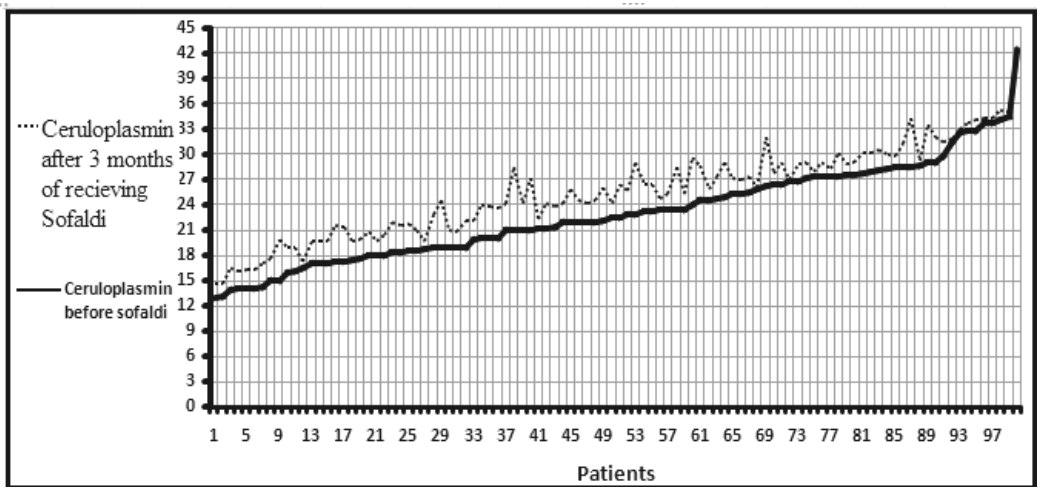

Figure 1 : Ceruloplasmin concentration level before and after receiving DAAS 
Table :(3) Shows ceruloplasmin concentrations in male and female.

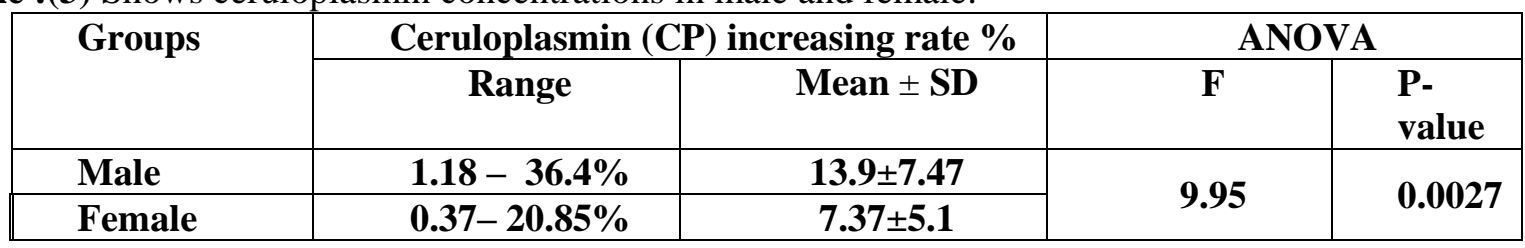

Table (3) Shows a statistically significant difference that Ceruloplasmin concentrations increasing rate is greater in male $(13.9 \pm 7.47 \mathrm{mg} / \mathrm{dL})$ than in females $(7.37 \pm 5.1 \mathrm{mg} / \mathrm{dL})(\mathrm{P}<0.05)$.

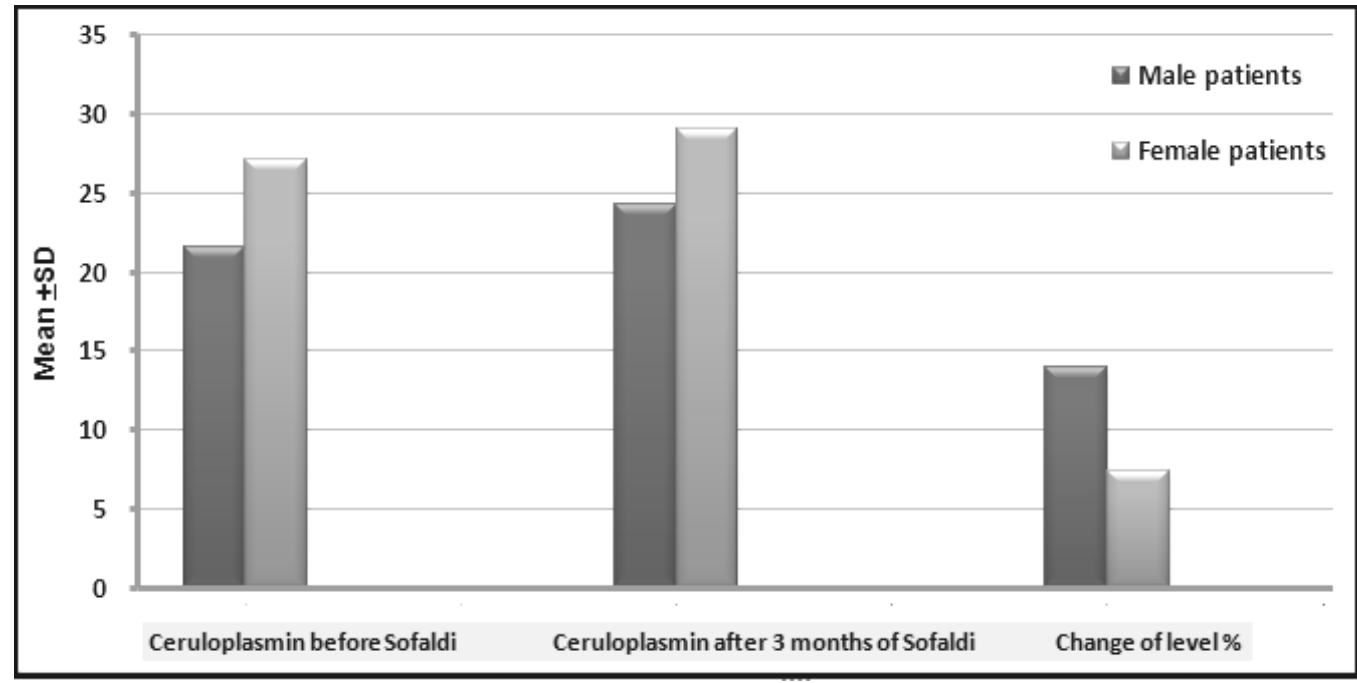

Figure 2: Comparison between males and females in ceruloplasmin level before and after receiving DAAS and rate of increase.

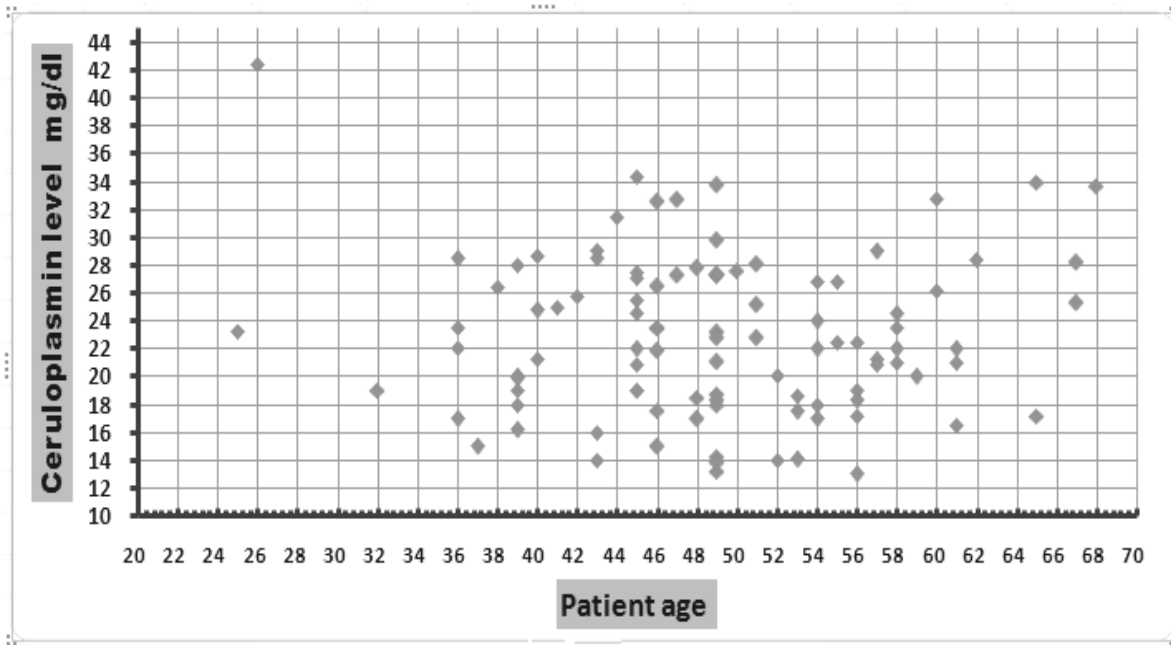

Figure 3: Correlation between Ceruloplasmin level and patients age

Table :(4) Shows ceruloplasmin concentrations and patient's age

\begin{tabular}{|l|c|c|c|c|}
\hline \multirow{2}{*}{ Groups } & \multicolumn{2}{|c|}{ Ceruloplasmin (CP) } & \multicolumn{2}{c|}{ ANOVA } \\
\cline { 2 - 3 } & Range & Mean \pm SD & F & P-value \\
\hline Male & $\mathbf{1 4}-\mathbf{4 2 . 4}$ & $\mathbf{2 3 . 6} \pm 5.99$ & \multirow{2}{*}{1.085} & \multirow{2}{*}{0.3} \\
\hline Female & $13-34$ & $22.49 \pm 5.3$ & & \\
\hline
\end{tabular}

Table (4) show no statistically significant difference between Ceruloplasmin and patient's age $<48$ yrs. . $(23.6 \pm 5.99 \mathrm{mg} / \mathrm{dL})$, and patients > 48yrs. $(22.49 \pm 5.3 \mathrm{mg} / \mathrm{dL})(\mathrm{P}>0.05)$. 


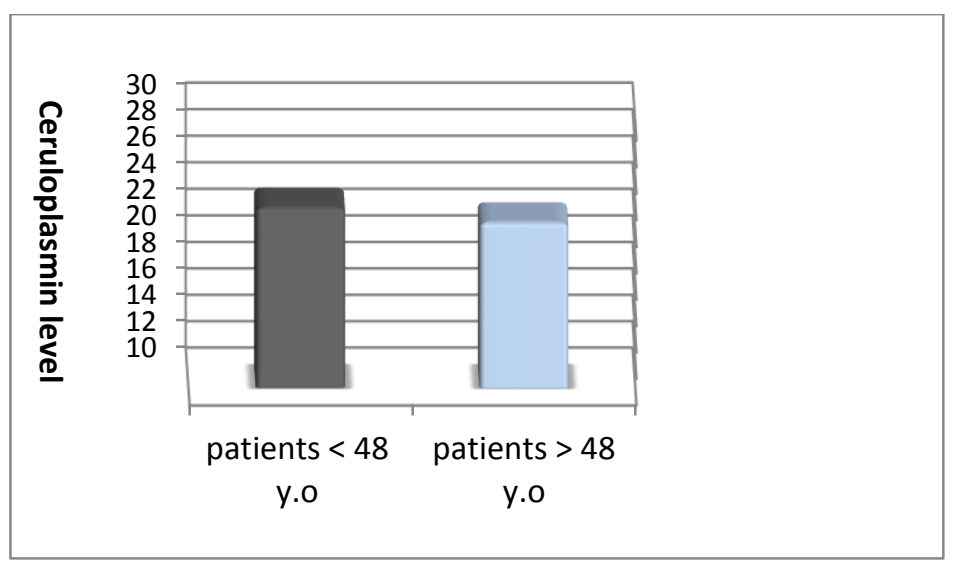

Figure 4 : Comparison between patients < 48y.o. and patients > 48 y.o. and ceruloplasmin level

\section{DISCUSSION}

Hepatitis C virus (HCV) is one of the major globally cause of death and morbidity, and it is still affects a substantial proportion of the Egyptian population $^{(\mathbf{1 - 2})}$.

The appearance of direct-acting antiviral agents (DAAs), which specifically target HCV proteins, has provided insights into the current situation, The use of protease inhibitors, such as Telaprevir, Boceprevir, Simeprevir, Faldaprevir and Vaniprevir, in combination with Peginterferon and Ribavirin has improved treatment efficacy in treatment-naïve patients $(70 \%$ to $80 \%)$ and in patients infected with HCV genotype 1 who have relapsed post-treatment ${ }^{(5)}$.

Patients with severe hepatitis were shown to have significantly lower levels of Ceruloplasmin compared to patients with other liver diseases, except for Wilson's disease ${ }^{(7)}$.

Among the noninvasive approaches used to assess responsiveness to treatment are the use of clinical symptoms and signs, routine laboratory tests (e.g., ALP, AST, ALT, GGT, PT), as well as ultrasonography and radiological imaging studies ${ }^{(9)}$.

This study involved a total of 100 individuals in one groups which recently discovered hepatitis $\mathrm{C}$ virus (HCV) and attending to hospital for further investigations and receive direct-acting antiviral agents (DAAs) (Daclatasvir \& Sofosbuvir) regimen, their age was ranged from 25 to 68 years with average of $(48.91 \pm 8.928 \mathrm{~kg}), 74$ males and 26 female.

All patient's lab results for hepatitis B virus (HBV), ANA, AIDS and alpha fetoprotein were negative. No Family history of Wilson disease, and by examination there is no ascites, lower limb edema or jaundice. They were vitally stable at time of examination, and females not pregnant and not on contraceptive pills.

The current study showed that there was no significant correlation between age and serum Ceruloplasmin levels, and Ceruloplasmin slightly high in female patients than male patients but the rate of concentration increasing is more in males than in female.
Data reported by Viorica et al. ${ }^{(11)}$ for a normal population note that femalespatients exhibited slightly higher Cp concentrations (ave \pm SD of $0.392 \pm 0.153$ $\mathrm{mg} / \mathrm{mL})$ than male patients $(0.319 \pm 0.123 \mathrm{mg} / \mathrm{mL})$, Results for a normal population by Viorica et al. ${ }^{(11)}$ indicated that does not seem to be a correlation between the $\mathrm{Cp}$ concentration and patient's age also ${ }^{(11)}$ indicate significantly higher concentrations of Ceruloplasmin in female patients which are known to be caused by use of oral contraceptives ${ }^{(\mathbf{1 2})}$.

Many studies search for the correlation between Ceruloplasmin and other disease or other acute phase reactant and some prove that Ceruloplasmin is a good marker for hepatic cirrhosis, elevated in cancer prostate or other carcinoma, as bile duct carcinoma and other found that Ceruloplasmin concentration in multiple sclerosis (MS) patients varies depending on different immunomodulatory treatment, but no studies touch on useful of Ceruloplasmin as a marker for responsiveness in treatment of hepatitis $\mathrm{C}$ Virus(HCV) as in this study ${ }^{(\mathbf{1 3})}$.

Multivariate analysis revealed that Ceruloplasmin levels were significantly related to liver cirrhosis, Combining Ceruloplasmin with serum GGT levels (CG model) was set up to predict significant fibrosis and liver cirrhosis in CHB patients with normal or minimally raised $\mathrm{ALT}^{(\mathbf{1 3 )}}$.

Several cross-sectional studies in the general population have shown that acute-phase reactants as Ceruloplasmin are positively correlated with inflammation or carcinoma as they improve that serum Ceruloplasmin may complement the biochemical screening in prostate carcinoma, especially in cases where this cancer is not accompanied by elevation of serum PSA. However, it is not of help in differentiating prostate cancer from prostate benign hyperplasia ${ }^{(\mathbf{1 4})}$.

Comparing cancer and normal bile duct tissue Ceruloplasmin had positive coefficients with a $\log 2$ ratio $>1$ for advanced $\mathrm{T}, \mathrm{N}$ stage and perineural invasion cancer tissue. Strong immune histochemical expression of Ceruloplasmin was dominant in tumors with advanced $\mathrm{T}$ stage and perineural invasion, Ceruloplasmin is supposed to be related with advanced 
Ceruloplasmin as a Predictor for Responsiveness...

T stage and perineural invasion, having a possibility as a candidate prognostic marker for bile duct cancer ${ }^{(15)}$.

Baseline serum Ceruloplasmin is an independent predictive factor for the progression of diabetic nephropathy in patients with type 2 diabetes mellitus (16). In another study they found Ceruloplasmin concentration in multiple sclerosis (MS) patients varies depending on different immunomodulatory treatment and decrease after 3 months of melatonin administration. Ceruloplasmin could be a valuable serum marker for the chronic demyelinating process participating in oxidative stress mechanisms, as well as a neurodegenerative marker, but not a marker of acute-phase MS ${ }^{(\mathbf{1 7})}$.

Up to present, no other reliable test or marker alone is sufficiently accurate in predicting responsiveness to treatment of patients with DAAS.

In this study, we investigated associations between serum ceruloplasmin concentration levels in chronic $\mathrm{HCV}$ patients before receiving DAAS and three months after. It has indicated that serum ceruloplasmin levels were slightly high after receiving DAAS and so we can use it as a marker to responsiveness to direct acting antiviral drugs.

\section{CONCLUSION}

It could be concluded that ceruloplasmin is proved to be a useful marker for responsive of patients to DAAS because it is increased shortly after receiving DAAS. The disadvantage of using ceruloplasmin as a marker is that it requires to be measured before starting of treatment because its concentration varies from person to person.

\section{REFERENCES}

1. Gower E, Estes C, Blach S et al. (2014): Global epidemiology and genotype distribution of the hepatitis $\mathrm{C}$ virus infection. J Hepatol., 61(1):S45-57.

2. Kandeel A, Mohamad G, Samir E et al. (2015): The prevalence of hepatitis $\mathrm{C}$ virus infection in Egypt. https://www.ncbi.nlm.nih.gov/pmc/articles/PMC5145777/

3. Ghany MG, Morgan TR, Wright EC et al. (2007): Impact of reducing peginterferon alfa-2a and ribavirin dose during retreatment in patients with chronic Hepatitis C. Gastroenterology, 132: 103-112.

4. Pawlotsky JM, Pellerin M, Bouvier M et al. (1998): Genetic complexity of the hypervariable region 1 (HVR1) of Hepatitis $\mathrm{C}$ virus (HCV): influence on the characteristics of the infection and responses to interferon alfa therapy in patients with chronic Hepatitis C. J Med Virol., 54: 256-264.

5. Rodriguez M, Stoehr A, Gane EJ et al. (2014): Combination of Vaniprevir with peginterferon and ribavirin significantly increases the rate of SVR in treatmentexperienced patients with chronic HCV genotype 1. Clin Gastroenterol Hepatol., 12:1029-37.

6. Kang JE, Jaechan L, Joong-Yeol P et al. (2015): Serum Ceruloplasmin Level as a Predictor for the Progression of Diabetic Nephropathy in Korean Men with Type 2 Diabetes Mellitus Diabetes Metab J., 39:230-239.

7. McCarthy RC, Kosman DJ(2013): Ferroportin and exocytoplasmic ferroxidase activity are required for brain microvascular endothelial cell iron efflux. J Biol Chem., 288: 17932-17940.

8. Yang X, Tong DJ, Liang J et al. (2005): Ceruloplasmin level of patients with liver disease in China. Zhonghua Nei Ke ZaZhi., 44: 13-15

9. Curzon G, Vallet L (1960): The purification of human caeruloplasmin. Biochem J., 74:279-287.

10. Ohta T, Sakaguchi K, Fujiwara A et al. (2006): Simple surrogate index of the fibrosis stage in chronic hepatitis $\mathrm{C}$ patients using platelet count and serum albumin level. Acta Med Okayama, 60(2): 77-84.

11. Viorica $L$, William $H$ and Kirk $L$ (2009): Ceruloplasmin levels in human sera from various diseases and their correlation with patient's age and gender. Health, 1(2): 104110.

12. Sontakke AN and More $U$ (2004): Changes in serum ceruloplasmin levels with commonly used methods of contraception. Indian J Clin Biochem., 19(1): 102-104.

13. Da-Wu Z, Jing D, Jia-Ji J et al. (2016): Ceruloplasmin, a reliable marker of fibrosis in chronic hepatitis B virus patients with normal or minimally raised alanine aminotransferase; World J Gastroenterol., 22(43): 9586-9594.

14. Fotiou K, Vaiopoulos G, Lilakos K et al. (2007): Serum ceruloplasmin as a marker in prostate cancer Minerva Urol Nefrol., 59(4):407-11.

15. Woong H, Jin-Young J, Wooil K et al. (2017): Ceruloplasmin as a prognostic marker in patients with bile duct cancer ; Oncotarget, 8 (17): 29028-29037.

16. Lee MJ, Chang HJ, Yu MK et al. (2015): Serum Ceruloplasmin Level as a Predictor for the Progression of Diabetic Nephropathy in Korean Men with Type 2 Diabetes Mellitus Diabetes Metab J., 39:230-239.

17. Adamczyk-Sowa $M$, Sowa $P$, Mucha $S$ et al. (2016): Changes in Serum Ceruloplasmin Levels Based on Immunomodulatory Treatments and Melatonin Supplementation in Multiple Sclerosis Patients. Med Sci Monit., 22:2484-91. 